\title{
DESIGN, DEVELOPMENT AND IMPLEMENTATION OF NOVEL IDEA OF MOTOR CONTROL USING WIRELESS COMMUNICATION
}

\author{
S. Siddharthy ${ }^{1}$, S. Muruganand ${ }^{2} *$ B. Dinesh Kumar ${ }^{3}$ \\ ${ }^{I}$ Research Scholar, Department of Electronics and Instrumentation, Bharathiar University. \\ sasiddm@gmail.com \\ ${ }^{* 2}$ Assistant Professor, Department of Electronics and Instrumentation, Bharathiar University. \\ *Corresponding Author Email: drsmbu2010@gmail.com \\ ${ }^{2}$ Assistant Technical Officer, University Data Center, Bharathiar University. \\ dineshtn86@gmail.com
}

\begin{abstract}
Low cost low power RF modem is very efficient in providing excellent communication at various ranges and also for low power applications. A novel idea of motor control using PWM technique has been developed and controlled using wireless RF transreceiver. The combination of transmitter and receiver is termed as RF transreceiver is used to exchange information in half duplex mode. The control of potentiometer from $0-5$ volts controls the speed of dc motor.PIC microcontroller is used for programming and it is downloaded to PIC microcontroller circuit used for wide range of applications the Max 232 is a driver used to convert TTL/CMOS logic to RS 232 levels when microcontroller is serially communicated with PC. Wireless technology using RF modem controls the motor in 30 meters range is very useful in remote and rural areas where we cannot visit directly and frequently and monitor certain parameters.
\end{abstract}

Keywords: RF Modem, DC Motor, PIC Microcontroller, PWM

\section{INTRODUCTION}

Wireless communication is the process of transferring information from main station to two or more substations without the intervention of electrical conductors called wires. It is easy to move devices if not tethered by any network cable [3]. It is also easy to construct a substation in the hill, remote, rural areas rather than connecting using copper wires. A radio modem transmits data many kilometers by a wireless connection to another radio modem over a point to point or multipoint link. More of today's wireless applications require battery power leads to more power consumption. RF modules are constructed for low power applications. Due to ease and many applications and advantages Wireless communications can be used to control and transmit also receive required important information which helps in the development and also to meet the needs and to preserve human resources from dangers [6] .Controlling the speed of any devices is done manually in industries and also in various sectors mainly in the field of agriculture in some distance in centimeters.

\section{BLOCK DIAGRAM}
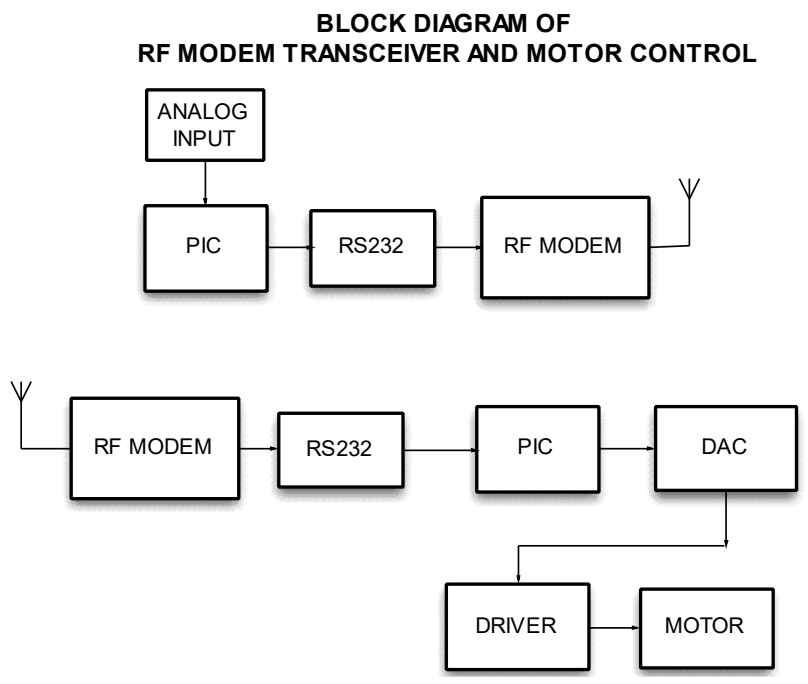

\section{MATERIALS AND METHODS}

The speed of the DC motor is controlled by Pulse Width Modulation (PWM) technique.PWM stands for pulse width modulation. The speed control using wireless technique unit consists of analog input, DAC board and driver circuit and motor. The DAC design consists of the latch 74LS273, DAC 0800, and the current to voltage converting circuit using opamp 741.DAC 0800 is configured for bipolar output operation. The output of the PIC will be high for certain frequency. Using potentiometer the current can be varied with this the motor can be controlled. Thus the varying speed is sent through wireless by RF mode 


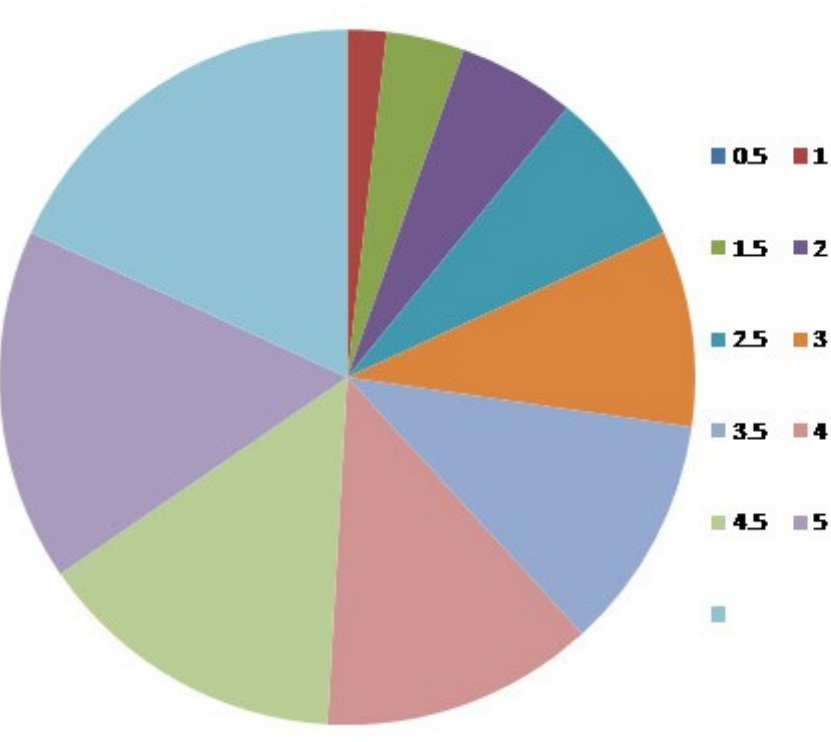

RF MODEM, 2.4 GHz, 30 MTS RANGE

RF modem is useful for many applications [1] [2] [4] [7] which is capable of two way wireless data transmission. The data rate of RF module is high and used for longer data transmissions. The RF Module is very useful and is a user interface module. The RF module can be embedded to any undergoing researches and PCB design. So wireless communication system can be implemented easily [5].

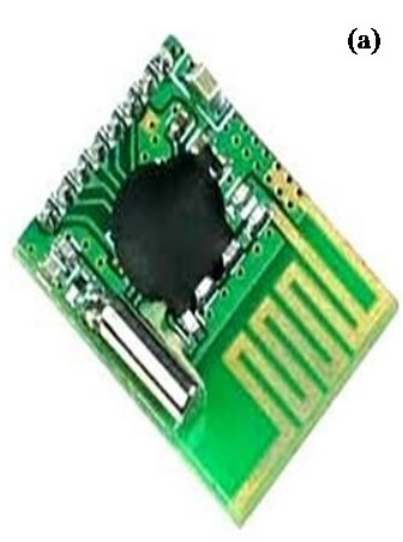

(a)

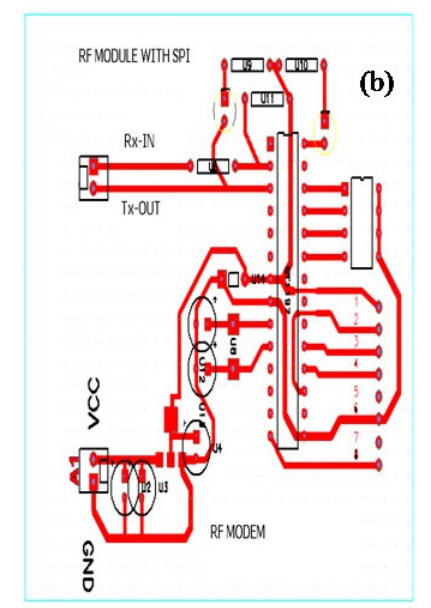

(a). RF Modem transreceiver

(b). PCB layout for RF modem used

For transmitting and receiving

\section{PIC MICROCONTROLLER}

PIC 16F877A is very useful for many versatile performances of various tasks in the field of electronics. PIC $16 \mathrm{~F} 877 \mathrm{~A}$ is precisely very cheap and easy for programming since it has high-performance RISC CPU [1]. It has an Operating speed DC - $20 \mathrm{MHz}$ clock input and DC - $200 \mathrm{~ns}$ instruction cycle.

\begin{tabular}{|l|l|}
\hline $\begin{array}{l}\text { Controlling voltage } \\
\text { V) }\end{array}$ & Duty cyde (\%) \\
\hline OV & 0 \\
\hline $05 \mathrm{~V}$ & 10 \\
\hline $1.0 \mathrm{~V}$ & 20 \\
\hline $15 \mathrm{~V}$ & 30 \\
\hline $20 \mathrm{~V}$ & 40 \\
\hline $25 \mathrm{~V}$ & 50 \\
\hline $3.0 \mathrm{~V}$ & 60 \\
\hline $35 \mathrm{~V}$ & 70 \\
\hline $4.0 \mathrm{~V}$ & 80 \\
\hline $45 \mathrm{~V}$ & 90 \\
\hline $5.0 \mathrm{~V}$ & 100 \\
\hline
\end{tabular}

\section{THE PRINCIPLE OF PWM}

For controlling the speed of a DC Motor, we need a variable voltage DC power source. If we consider $12 \mathrm{v}$ motor and switch on the power to it, the motor starts to speeding. Motors do not respond immediately so it takes an adequate time to reach full speed. If we switch the power off sometime before the motor reaches full speed, then the motor will start to slow down. If we continuously switch the power low and high quick enough, the motor will not settle immediately. It will run at some speed part way between zero and full speed. A PWM controller has the same principle. It switches the motor from series of pulses. It modulates the width of the pulses .So Pulse Width Modulation is used for motor control.

\section{Speed Control of DC Motor Using PWM}

DC motors are mainly used in industrial applications and agricultural aspects etc. In this regard the control of the distance in wide distances is very much important. In this scenario motor plays a major role [8]. Therefore we need to control the motor for our needs. Our aim is to control the speed of the DC motor using wireless communication. The speed of DC motor is controlled by voltage, armature resistance and flux etc. But in this project we control the speed of the DC motor by Pulse Width Modulation (PWM) technique. The voltage is controlled by the duty cycle of the PWM signal [9]. The duty cycle is referred to as [10]

Duty cycle $=\frac{\text { On Time }}{\text { Period }} \times 100$

From this method it can be obtained by smooth speed variation without reducing the starting torque of the motor. PWM techniques also eliminate harmonics. The DAC output is given to inverting terminal of IC 741 for amplification and output is given to driver IC ULN 2003 for controlling the motor. 

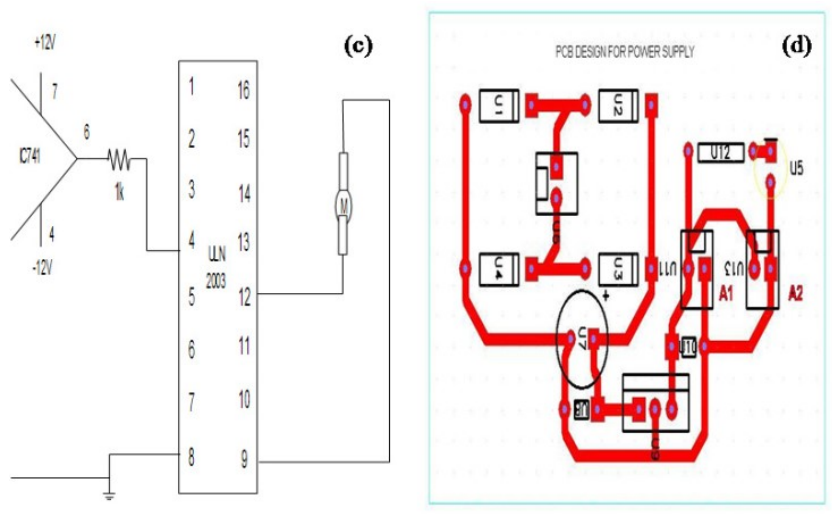

(c). Driver circuit

(d). PCB layout for power supply

\section{CONCLUSION}

The essential aim of this project is to design a motor control system which enables to monitor in an industry also agricultural aspects by using RF modem and display. The components used in the circuits are readily available. The PCB layouts are designed as supporting circuits and fully tested with full functionality in working environment. The wireless motor control is essentially a design and implementation project of wireless technology. Finally we are very well succeeded in controlling the motor which is very useful in the places where we can preserve the human resources from risky environment.

The project is very simple, and this simplicity leads to many useful, reliable and helpful for the society is the satisfactory minds of any individual.

\section{FUTURE SCOPE}

RF for motor control can also be implemented in SOC(System On Chip )for even more sophistication and very useful for the society[2].SOC technology is the packaging of all the obligatory electronic circuits and parts of a system on a single integrated circuit(IC)generally known as micro chip.

\section{REFERENCES}

[1] Pradeep Kumar Somasundaram1 and Dharon Joseph Ediosn "Monitoring Water Quality using RF Module" International Journal of Application or Innovation in Engineering \& Management Volume 2, Issue 7, July 2013.

[2] Manos M. Tentzeris, John Papapolymerou and N. Papageorgiou "3-D-Integrated RF and MillimeterWave Functions and Modules Using Liquid Crystal Polymer (LCP) System-on-Package Technology" IEEE Transactions On Advanced Packaging, Vol. 27, No. 2, May 2004.

[3] Mbonu E.S, Uzedhe G.O and Nwafor C. M. "Radio Frequency Transceivers: A Better Replacement For Data Cables In Computer Based Dot Matrix Display Systems" Academic Research International ISSN-L: 2223-9553, ISSN: 2223-994,Vol. 2, No. 2, March 2012.
[4] Varun Goyal, Mr.Ajay Mudgil and Mrs.Divya Dhawan "Design And Implementation Of Virtual Fencing Using Rf Module" International Journal of Engineering Research \& Technology (IJERT)Vol. 1 Issue 3, May 2012 ISSN: 2278-0181

[5] Muktha Shankari K, Jyothi K, Manu E O, Naveen I P, Harsha Herle5 "Wireless Automatic Water Level Control using Radio Frequency Communication" International Journal of Advanced Research in Electrical, Electronics and Instrumentation Engineering Vol. 2, Issue 4, April 2013.

[6] Abu saleh Md. Tayeen,A.F.M Sultanul Kabir and Razib Hayat Khan "Mobility Assisted solutions for Well known attacks in Mobile Wireless Network" International Journal of Computer Science and Information Security Vol. 9,No. 5,May 2011.

[7] Ethem M. Sozer, Milica Stojanovic, and John G. Proakis "Underwater Acoustic Networks" IEEE Journal of Oceanic Engineering, vol. 25, no. 1, January 2000.

[8] Sudip K. Mazumder and Kaustuva Acharya" Rotor Position Feedback Over an RF Link for Motor Speed Control" IEEE Transactions on Power Electronics, vol. 25, no. 4, April 2010.

[9] Atul Kumar Dewangan, Nibbedita Chakraborty, Sashi Shukla, Vinod Yadu " PWM Based Automatic Closed Loop Speed Control of DC Motor" International Journal of Engineering Trends and TechnologyVolume3Issue2- 2012 ISSN: 2231-5381.

[10] Dr. Jamal A. Mohammed " Pulse Width Modulation for DC Motor Control Based on LM324 “Eng. \&Tech. Journal, Vol. 31,Part (A), No.10, 2013. 